\title{
Enhancing Noise Attenuation in Exhaust Mufflers on Response to Baffle Configuration
}

\author{
Ahmed Elsayed ${ }^{\text {a,c }}$, Christophe Bastien ${ }^{\text {b }}$, Humberto Medina ${ }^{\mathrm{c}}$, Steve Jones ${ }^{\text {a }}$, Hassan \\ Kassem $^{\text {d }}$ \\ ${ }^{a}$ Institute for Advanced Manufacturing Engineering (AME) \\ ${ }^{b}$ Centre for Mobility and Transport, Coventry University \\ ${ }^{c}$ School of engineering and computing, Coventry University \\ ${ }^{d}$ School of Mathematics, Computer Science and Engineering, City University London
}

\begin{abstract}
Using baffles in exhaust mufflers is known to improve transmission loss and reduce the noise emitted to the environment. This paper postulates that baffle cut ratio affects the muffler performance in the same effect as a shell-and-tube heat exchanger, consequently the baffle cut ratio should affect the muffler performance. This study presents a parametric study on the effect of baffle configuration on predicted transmission loss and pressure drop. The effect of baffle cut ratio, baffle spacing, number of baffle holes, and hole pattern distribution on transmission loss was investigated. Results showed that reducing the baffle cut ratio increased the transmission loss at intermediate frequencies by up to $45 \%$ while decreasing the spacing between muffler plates improved the muffler transmission loss by $40 \%$. The assessment of the baffle effect on flow using a thermal baffle approach model indicated a sudden drop in fluid temperature in axial flow direction by $15 \%$ as the baffle cut ratio changed from $75 \%$ to 25 . To the best of authors knowledge, the effect of baffle cut ratio configuration on acoustic response and back pressure has not been previously reported or investigated.
\end{abstract}

Index Terms: Baffles, Exhaut systems, Transmission Loss.

(C) 2017 Published by MECS Publisher. Selection and/or peer review under responsibility of the Research Association of Modern Education and Computer Science.

\section{Introduction}

Transmission loss (TL) is usually measured using the three-point approach (decomposition method) or four pole methods; the four pole method is carried out by a two-source method and two-load method [1]. Several numerical approaches have been used to model TL in exhaust mufflers such as finite element software: Actran [2] and COMSOL Multiphysics[3], Boundary element methods (BEM) using Coustyx [4], and transfer matrix

* Corresponding author. Tel.:

E-mail address: ahmed.elsayed.1981@gmail.com 
approach using Ricardo wave [5;6;7].

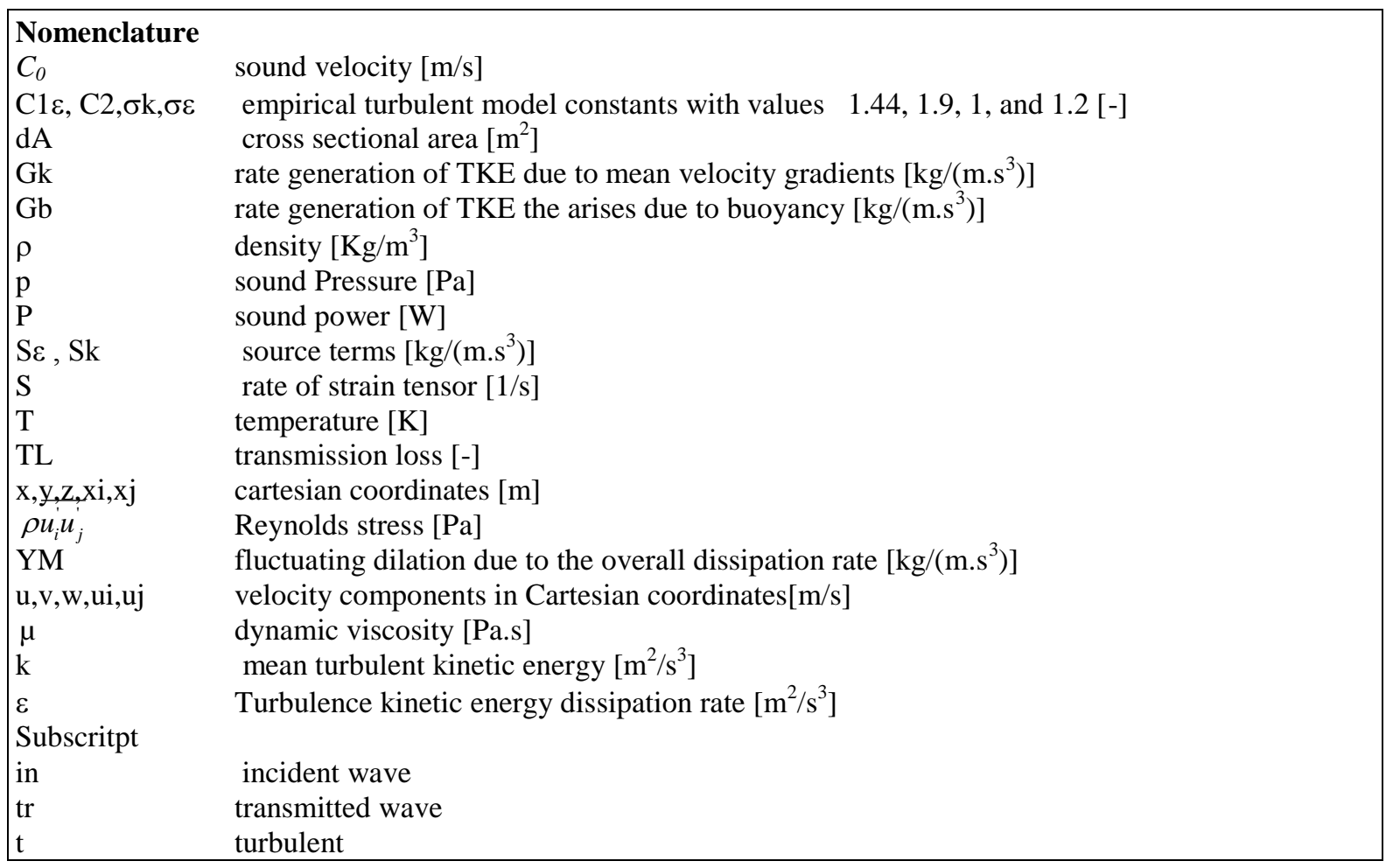

Using baffles in exhaust mufflers have been reported to enhance the TL of muffler by more than 50\% [8; 9; 10]. Roy [11] investigated the effect of internal completely circular baffles with single centred holes on the transmission loss using harmonic Boundary Element Method (BEM) with and without extensions on baffles. It was found that the TL in the lower frequency spectrum is reduced while the mid to high frequency spectrum is greatly increased using baffles. Horoub [12] investigated the effect of tapered connected expansion chambers by connecting different sizes of expansion chambers. Computational Fluid Dynamics (CFD) studies for the several connected expansion chambers showed that extension on baffles reduced the pressure drop in the muffler compared to single expansion chamber of the same size due to the reduction in the secondary flow losses and separations [13]. Other studies investigated the effect of baffle spacing on the Sound Pressure Level (SPL) [14] showing that reducing spacing between baffle reduced the SPL. Another parameter that was investigated by Gupta and Tiwari [15] was the effect of hole arrangements in perforated tubes on transmission loss.

Ricardo-wave is a one-dimensional gas dynamics code based on finite volume method for simulating engine cycle performance. It is widely used by automotive and exhaust manufacturers such as Eberspächer [16; 17] and Jaguar-LandRover (JLR) [18]. Also, COMSOL Multiphysics modelling software is widely known for its capability to model transmission loss of different mufflers such as reactive, absorptive and hydride mufflers. Therefore, Ricardo-wave and COMSOL Multiphysics have been proposed for the prediction of TL in this study to investigate the effect of baffle configuration on both TL and back pressure in exhaust mufflers as it has not been previously reported. This paper highlights the effect of geometrical baffle configurations associated with four main parameters; baffle cut ratio, number of holes, holes distribution and baffle spacing. 


\section{Tested Configurations and Methodology}

The effect of three baffle cut-off ratio configurations was investigated, as depicted in Fig. 1. The muffler chamber length was $202.2 \mathrm{~mm}$ with a diameter of $153.289 \mathrm{~mm}$. The muffler inlet and outlet pipes diameters were the same as muffler dimensions used in experimental validation section $(104.78 \mathrm{~mm})$.

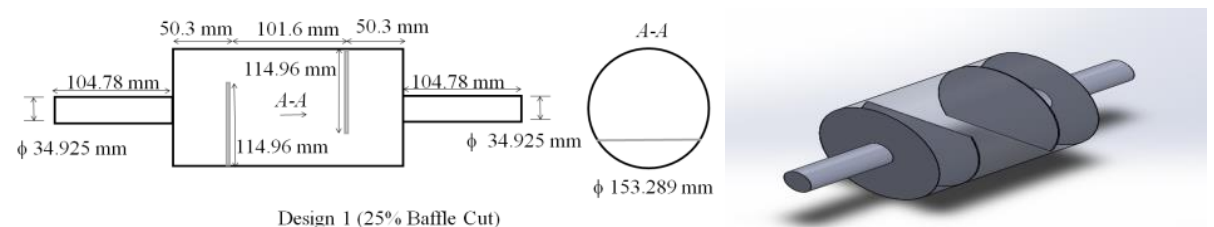

Design 1(Baffle cut ratio 25\%)

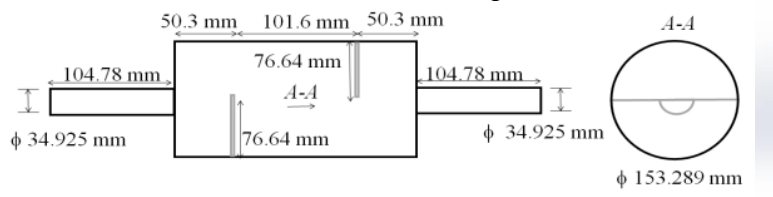

Design $2(50 \%$ Baffle Cut $)$

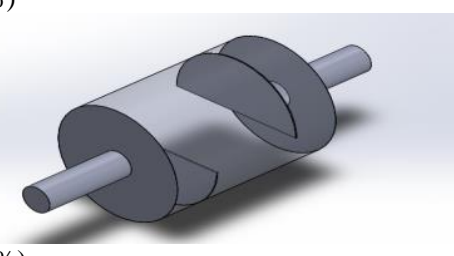

Design 2(Baffle cut ratio $=50 \%)$
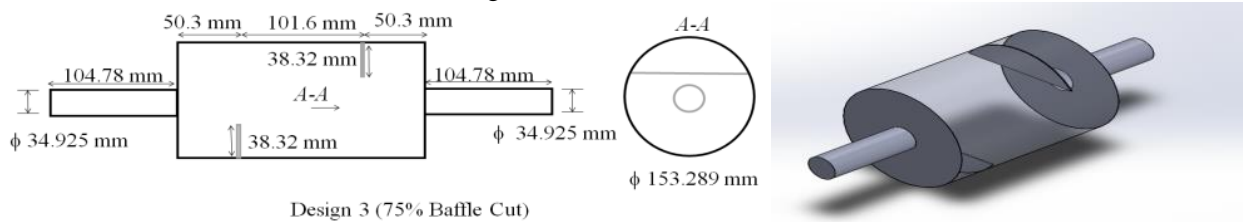

Design 3 (Baffle cut ratio 75\%)

Fig.1. Baffle Cut Ratio Configurations and Their Middle Section A-A

A fixed baffles spacing of $101.6 \mathrm{~mm}$ was used in investigation the effect of the baffle cut ratio. The small baffle spacing was investigated with half of this distance positioning the $50 \%$ cut ratio baffle at $50.80 \mathrm{~mm}$ spacing. To investigate the effect of holes' number, the number of holes was changed from 1 hole up to 5 holes, ensuring that the hole was centred to the muffler baffles for all configurations as presented in section 6 . The hole diameter used was $34.925 \mathrm{~mm}$ and positioned at the centre of the baffles.
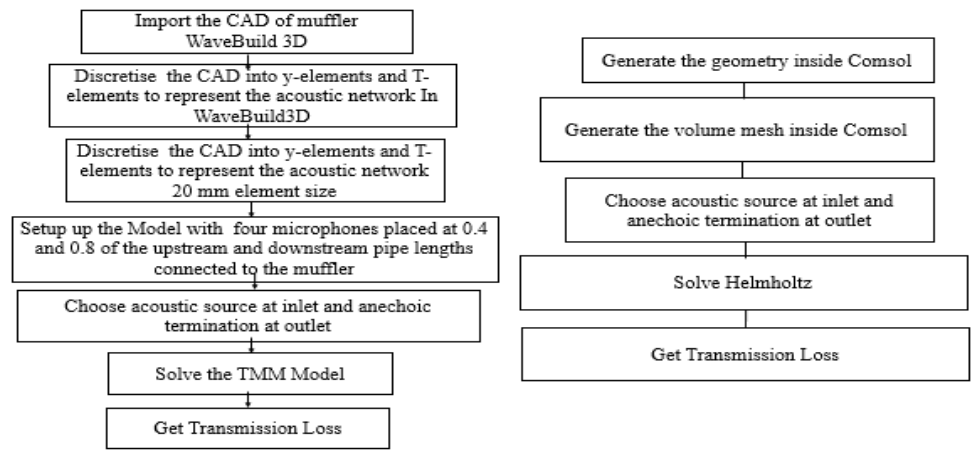

Fig.2. Methodology of Acquiring Muffler Transmission Loss (Ricardo Wave - Left and COMSOL- Right) 
For arrangements with more than one single hole, holes were arranged on a pitch circle radius of $47.9 \mathrm{~mm}$ with keeping one hole at the centre. Regarding the effect of baffle distribution, two configurations were investigated. The first one considered three inline holes each of $34.925 \mathrm{~mm}$ diameter with one of the holes fixed in the centre. The second configuration had three holes with a diameter of $34.925 \mathrm{~mm}$ distributed on a pitch circle radius of $47.9 \mathrm{~mm}$ without any holes in the centre. Fig. 2 illustrates the methodology of handling the Computer Aided Design (CAD) geometry to post-processing of the TL in both software. In order to visualize the flow effects, computational fluid dynamics (CFD) simulations were performed using OpenFoam 2.3.x, which has a CFD solver based on control volume discretization, to assess the effect of the baffles on the flow. Compressible steady state solver rhoSimplecFoam was used. Inlet velocity of $45 \mathrm{~m} / \mathrm{s}$ and outlet pressure of 1.1 bars were used. The baffle thermal conductivity was set to $16 \mathrm{~W} / \mathrm{m} . \mathrm{K}$, the specific heat to $490 \mathrm{~J} / \mathrm{kg} . \mathrm{K}$ and density of $8000 \mathrm{~kg} / \mathrm{m}^{3}$. In order to ensure robust convergence and accurate results, a relative tolerance of $10^{-8}$ was used. A relaxation factor of 0.3 was selected for all variables except pressure and density, where a value of 0.9 was used. The Reynolds-averaged Navier-Stokes equation (RANS) approach has been chosen in the Turbulence analysis. The flow was assumed to be a compressible steady state ideal gas, the gravity effects and source terms were neglected and the forced convection was selected to dominant. Viscosity was calculated based on a Sutherland model; velocity inlet and pressure outlet were utilized. The turbulent model used within RANS is the k-epsilon realizable, which is suitable to model flows involving rotation, boundary layers under strong adverse pressure gradients, separation, and recirculation. The realizable k- $\varepsilon$ model has been selected to simulate the flow turbulence as it demonstrates a superior ability to capture the mean flow of the complex structures [19]. The mesh was adjusted so that y+ values were above 25-30 (below 75) in order to model the turbulence accurately.

The Compressible Continuity equation 1:

$$
\frac{\partial(\rho u)}{\partial x}+\frac{\partial(\rho v)}{\partial y}+\frac{\partial(\rho w)}{\partial z}=0
$$

Momentum equation 2:

$$
\frac{\partial}{\partial x}\left(\rho u_{i} u_{j}\right)=-\frac{\partial p}{\partial x_{i}}+\frac{\partial}{\partial x_{j}}\left[\mu\left(\frac{\partial u_{i}}{\partial x_{j}}+\frac{\partial u_{j}}{\partial x_{i}}\right)\right]-\frac{\partial}{\partial x_{j}}\left(\rho \overline{u_{i}^{\prime} u_{j}^{\prime}}\right)
$$

Transport equations 3 and 4 for the turbulence energy generation and dissipation rates [20]:

$$
\begin{aligned}
& \frac{\partial\left(\rho k u_{j}\right)}{\partial x_{j}}=\frac{\partial}{\partial x_{j}}\left[\left(\mu+\frac{\mu_{t}}{\sigma_{k}}\right) \frac{\partial k}{\partial x_{j}}\right]+G_{k}+G_{b}-\rho \varepsilon-Y_{M}+S_{K} \\
& \frac{\partial}{\partial x_{j}}\left(\rho \varepsilon u_{j}\right)=\frac{\partial}{\partial x_{j}}\left[\left(\mu+\frac{\mu_{t}}{\sigma_{\varepsilon}}\right) \frac{\partial \varepsilon}{\partial x_{j}}\right]+\rho C_{1} S \varepsilon-\rho C_{2} \frac{\varepsilon^{2}}{k+\sqrt{v \varepsilon}}+C_{1 \varepsilon} \frac{\varepsilon}{k} C_{3 \varepsilon} G_{b}+S_{\varepsilon}
\end{aligned}
$$

$\mathrm{G}_{\mathrm{k}}$ represents the rate generation of Turbulent Kinetic Energy (TKE) that arises due to mean velocity gradients, $G_{b}$ being the rate generation of turbulent kinetic energy the arises due to buoyancy, and $Y M$ represents the fluctuating dilation in compressible turbulence that contributes to the overall dissipation rate. $\mathrm{S}_{\varepsilon}$ and $S_{k}$ are source terms defined by the user. 
The sound pressure p, was calculated with HelmHoltz equation using COMSOL by equation 5 [3]:

$$
\nabla\left(\frac{1}{\rho_{0}} \nabla p\right)+\frac{k^{2} p}{\rho_{0}}=0
$$

$k=2 \omega \mathrm{f} / \mathrm{c}_{0}$ is the wave length, $\rho_{0}$ is the density of the air, and $C_{0}$ is the speed of sound. The TL is usually referred as a muffler characteristic property, not dependent on the internal flow conditions. TL (equation 6) is defined as the incident sound (equation 7) over transmitted sound powers (equation 8).

$$
\begin{gathered}
T L=10 \log \left(\frac{P_{i n}}{P_{t r}}\right) \\
P_{i n}=\int \frac{p_{i}^{2}}{2 \rho c_{0}} d A \\
P_{t r}=\int \frac{p_{t r}^{2}}{2 \rho c_{0}} d A
\end{gathered}
$$

\section{Validation of Baffle Modelling in Ricardowave and COMSOL}

Double chamber exhaust chamber with the dimensions previously reported [4] was used for validation, the diameters of pipes used were $34.925 \mathrm{~mm}$, and $153.289 \mathrm{~mm}$. The model has been built up in Ricardo wave with mesh $20 \mathrm{~mm}$ element sizes. The software predicted the experimental transmission loss with good agreement for most frequency ranges, as depicted in Fig. 3. It can be observed that both finite element models using COMSOL Multi-physics and Ricardo Wave predicted the TL of experimental data accurately over a wide range of operating frequencies.

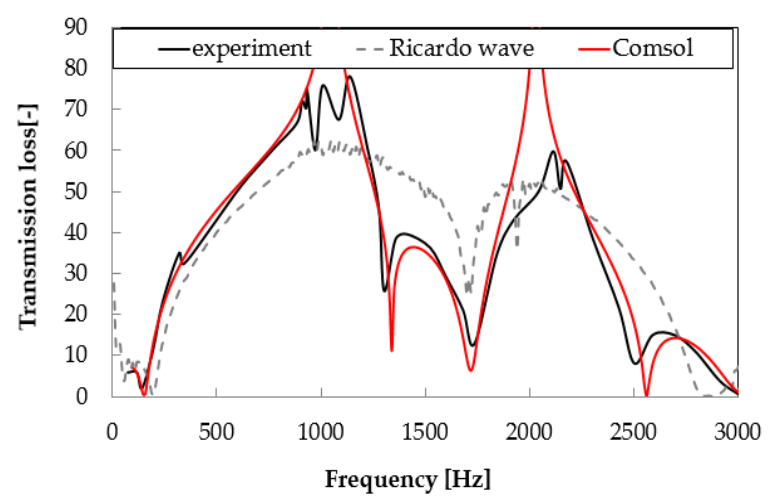

Fig.3. Validation of Double Chamber

\section{Effect of Baffle Cut-off Ratio}

The effect of baffle configuration on the transmission loss using Ricardo-wave and COMSOL Multi-physics 
is presented in Fig.4 to Fig. 6. It can be observed that reducing the baffle size shifted the TL peak to a higher frequency. Also, mufflers with large baffle sizes were more efficient in the intermediate frequency region of design 1 (25\% baffle cut ratio) than design 2 (50\% baffle cut ratio) and design 3 (75\% baffle cut ratio) $(60 \%$ improvement at frequency 1200). This may be attributed to the increased possibility of wave reflections in each muffler chamber leading to a reduction in the source noise and enhancement in the transmission loss. This technique is more effective at low traveling speed sound waves (low and intermediate frequencies). As the baffle size became smaller, increasing the wave frequency could help in enhancing the transmission loss by increasing the wave reflections as the wave travels faster for the same chamber length.

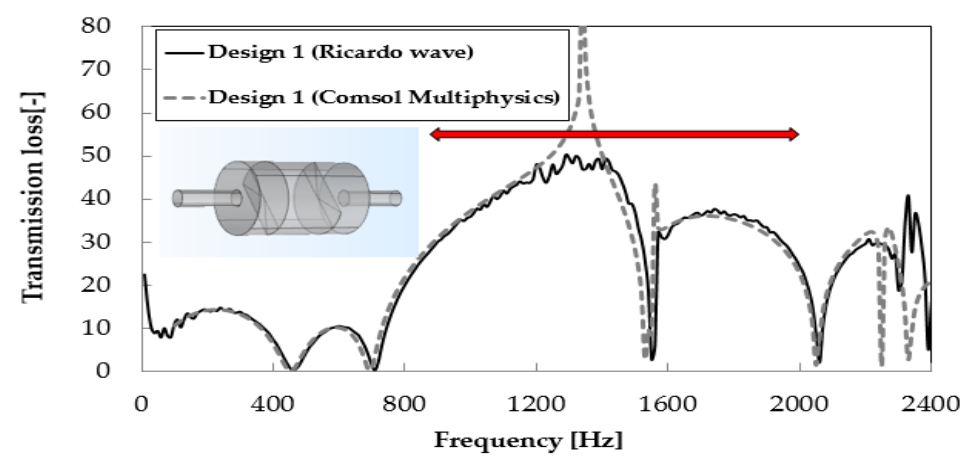

Fig.4. Transmission Loss Design 1

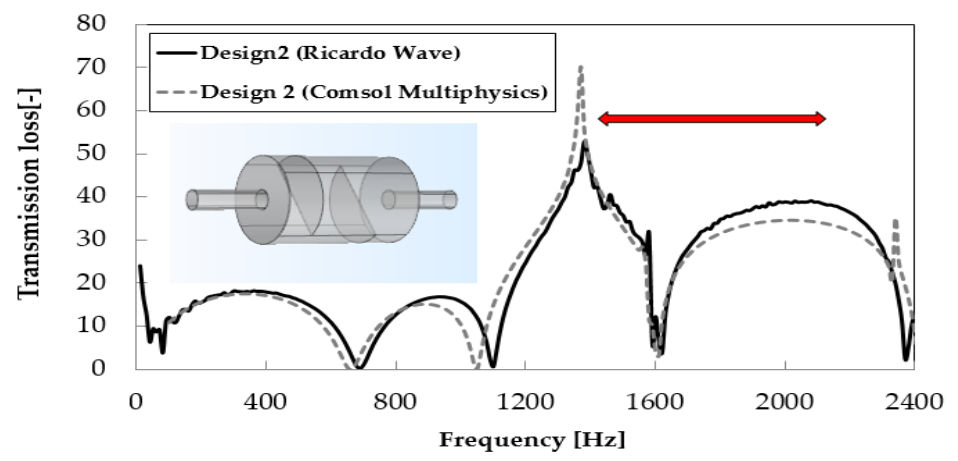

Fig.5. Transmission Loss Design 2

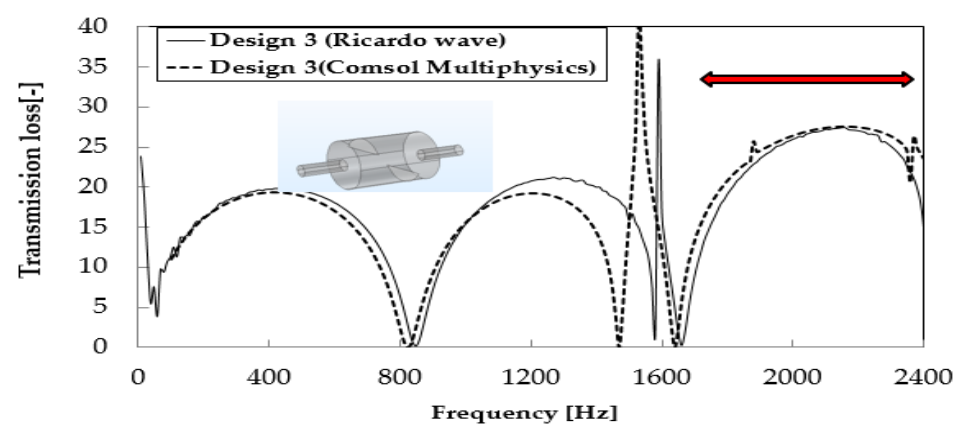

Fig.6. Transmission Loss Design 3 
The effect of the baffle cut ratio showed a clear dropping in the gas temperature due the axial conduction in the baffle. It was found that the larger the baffle size, the lower outlet gas temperature (Fig. 7). In design 1 and 2 , the temperature increased near the baffle due to the conversion of dynamic head and reduction of velocity because of the geometry change in the fluid domain, leading to an increase in static pressure and temperature rise. After the baffle, there was a temperature drop due to both the heat transfer to the baffle and the drop in the static pressure behind the baffle. In design 3 the baffle height (baffle diameter-centre/baffle tip distance) was small and without changing the direction of the core fluid at the centre of the muffler, the flow path length was considered to have less influence than other geometries leading to a higher outlet temperature compared to other configurations.

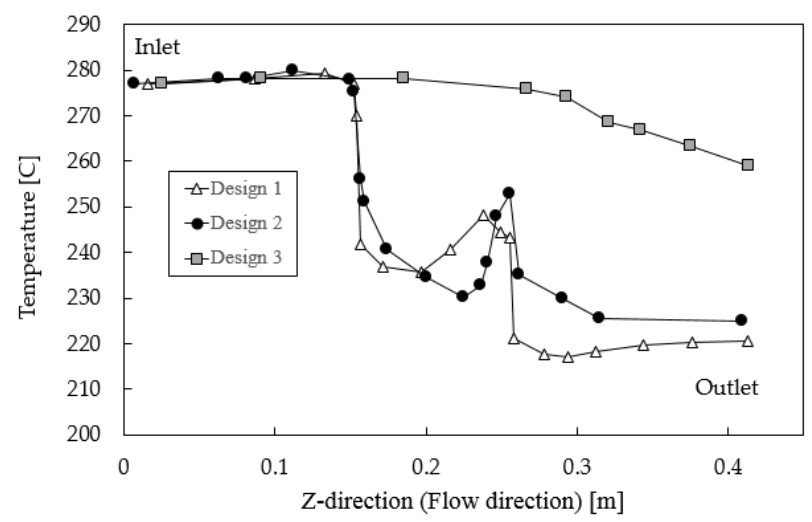

Fig.7. Temperature Change in Flow Direction

The flow with large baffle sizes exposed to large changes in direction compared to other configurations, as depicted in Fig. 8 and 9, leading to larger pressure drop and lower outlet temperatures from the muffler, which was also confirmed by Fig. 10. Using a half baffle cut could improve the performance from both an acoustic and pressure drop combination.

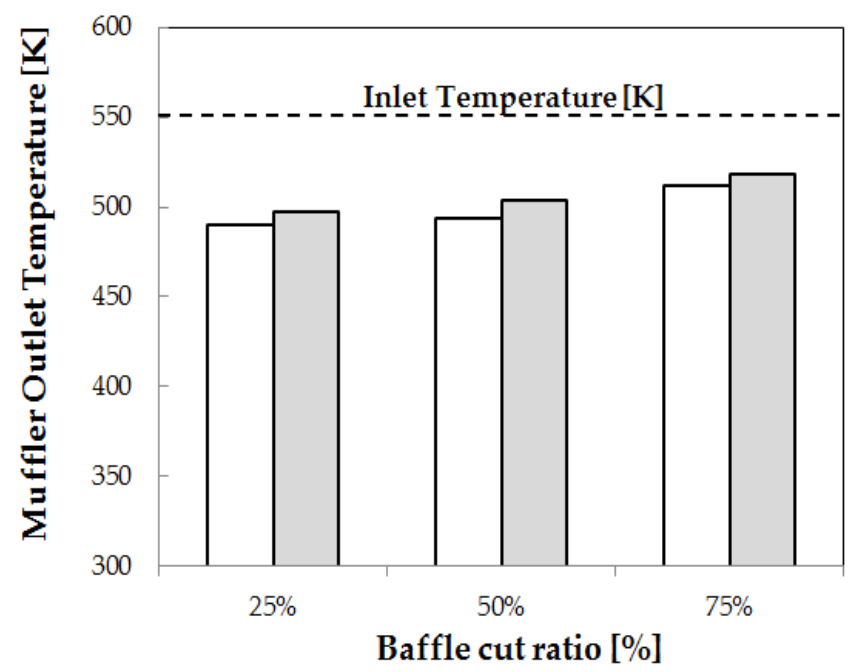

Fig.8. Effect of Baffle Cut on Back Pressure 


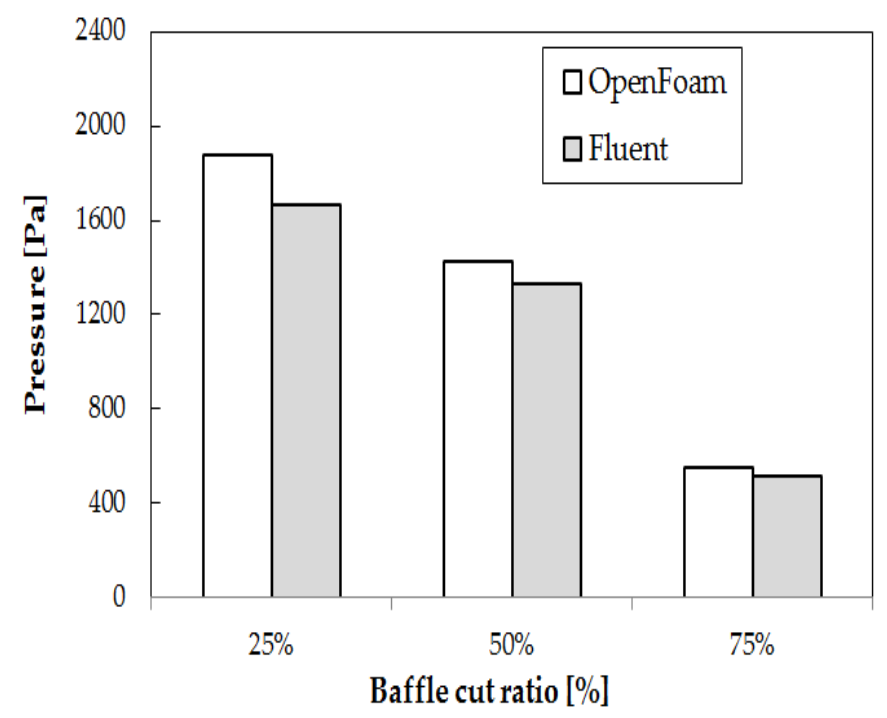

Fig.9. Effect of Baffle Cut on Outlet Temperature

\section{Effect of Number of Holes}

The performance of a single hole regarding TL was found to be enhanced in case of a single hole than a higher number of holes, as shown in Fig. 11. The throttling of fluid through a single hole helped to damp the noise through an increased number of reflections in each chamber volume as there was only single connection between different chamber volumes. The damping of noise was apparent at intermediate sound wave speed resulting in increased number of wave reflections and noise cancellation. However, using two or three holes is recommended to reduce the back pressure without much deterioration in transmission loss. Throttling the flow through single hole could lead to excessive pressure loss and deterioration of engine performance; passing the flow through multi-holes introduces the flow through parallel paths that helps to reduce the back pressure with some loss in acoustic performance as the transmission loss decreases with increasing the number of holes.

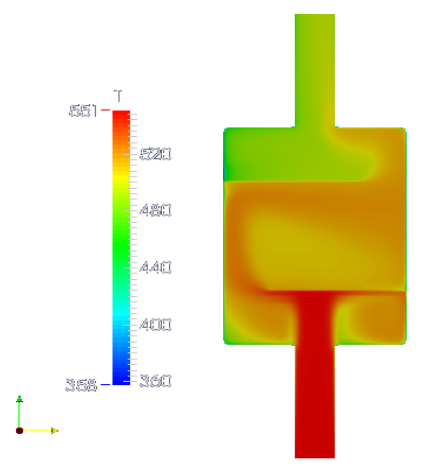

$25 \%$ Baffle cut ratio (design1)

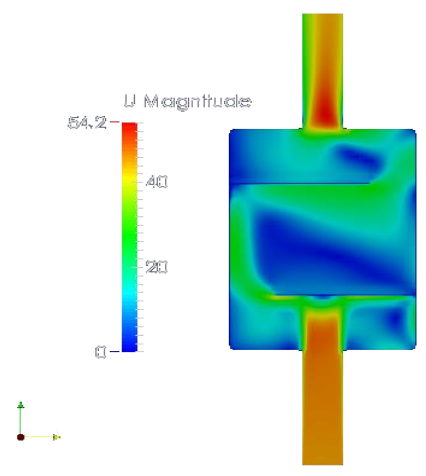

$25 \%$ Baffle cut ratio (design 1) 


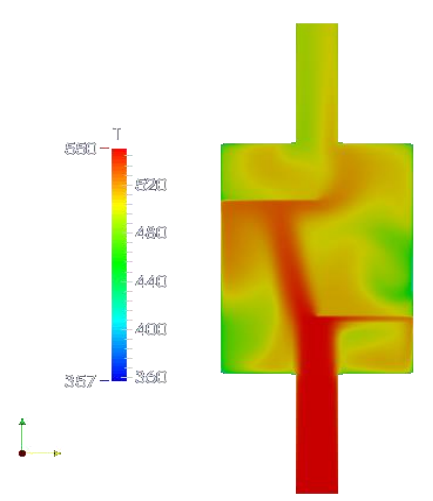

$50 \%$ Baffle cut ratio (design2)

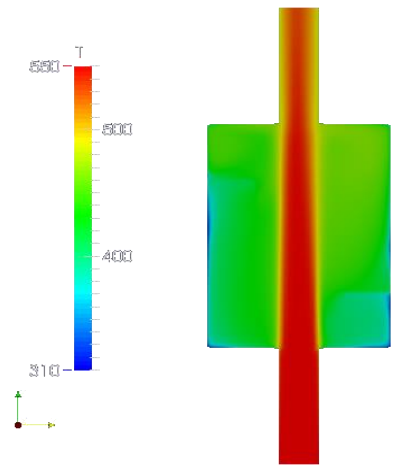

$75 \%$ Baffle cut ratio (design3) Temperature distribution

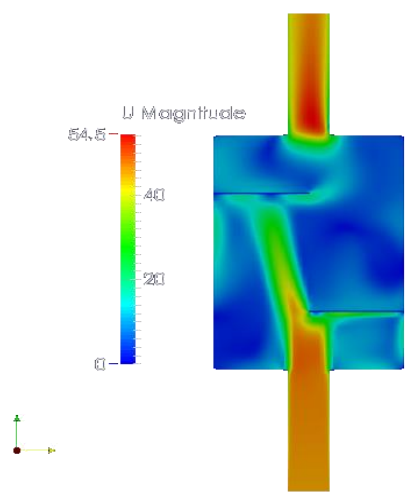

$50 \%$ Baffle cut ratio (design 2)

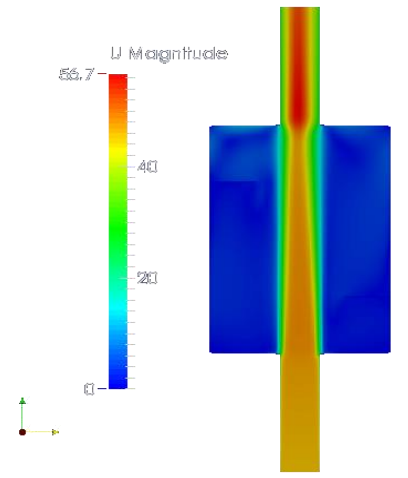

$75 \%$ Baffle cut ratio (design3) Velocity Magnitude

Fig.10. Temperature and Velocities through Different Designs

\section{Arrangement of Hole (Distribution of Holes from the Centre of the Baffle)}

Two designs were investigated with the same number of holes and holes diameters. It was observed that holes placed at the centre of baffles enhanced the TL in the middle frequency range as shown in Fig. 12. It is desirable for a high performing muffler to achieve high TL with less back pressure to avoid engine losses. The creation of centre holes could secure the return of reflected wave close to the inlet chamber and enhances the noise attenuation. 


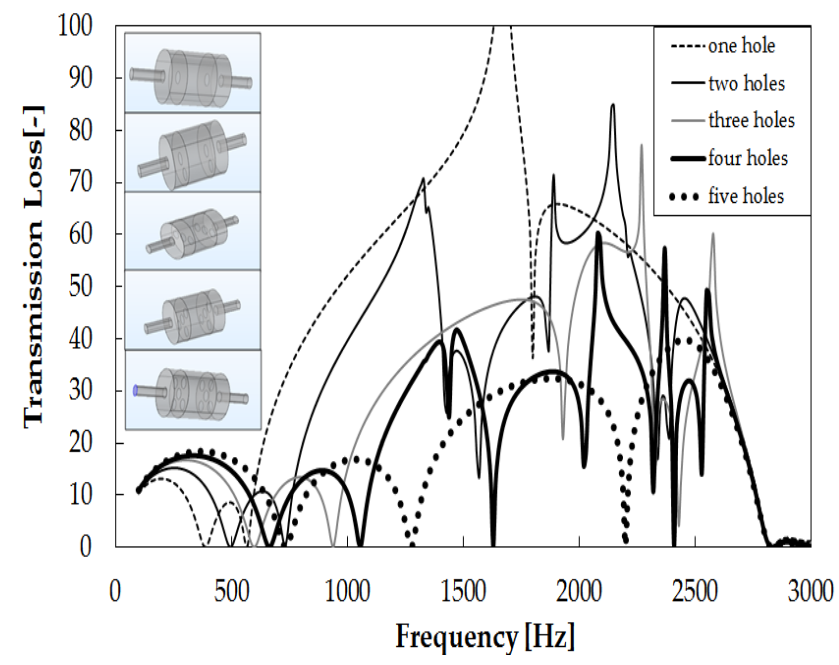

Fig.11. Effect of Number of Holes with Centered Hole

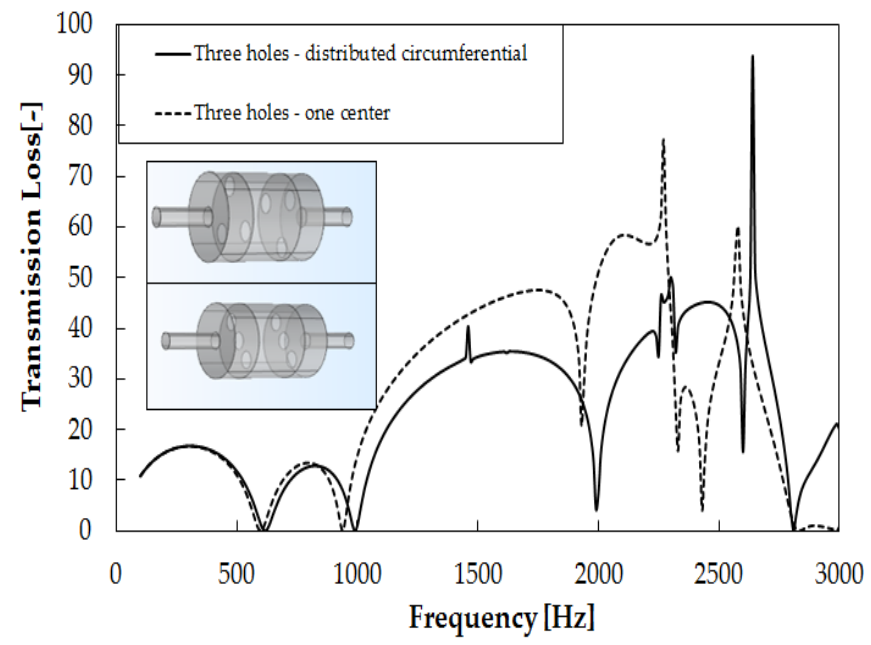

Fig.12. Effect of Three Holes Distribution on Baffles

\section{Baffle Spacing}

Closer baffle spacing enhanced the TL at intermediate and high frequencies ranges as shown in Fig. 13. This could be attributed to the smaller gap (SG) between the baffles having the effect of throttling the fluid and dampens the noise through small cross sections [21;22]. The attenuation is evident at intermediate and high frequencies as the sound wave travelled with high speed in same small gaps increasing the number of wave reflections with muffler wall and helped to reduce the noise in the incident waves. 


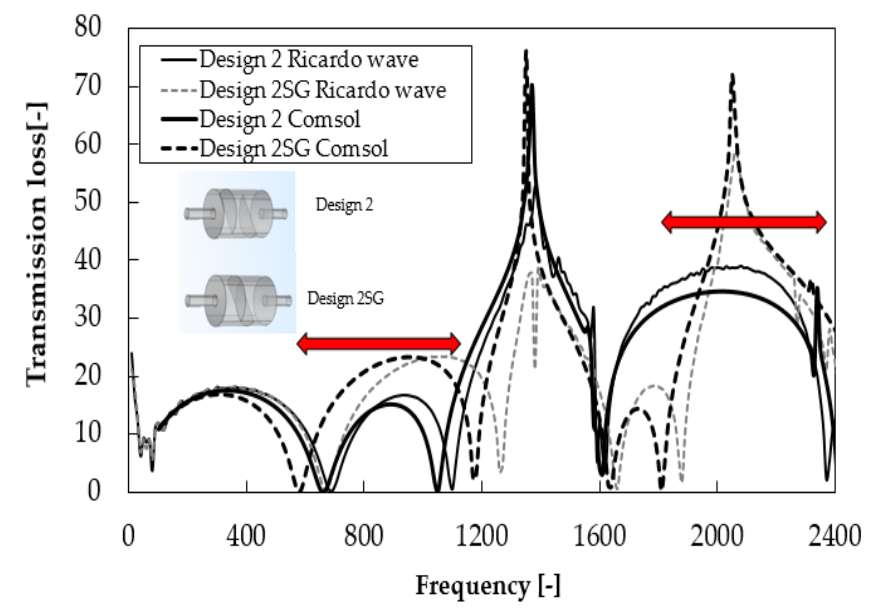

Fig.13. Effect of Baffle Spacing on Transmission Loss

\section{Conclusions}

The presented work investigates the effect of baffle size on muffler transmission loss and back pressure. The study highlights some design parameters on transmission loss that has not been covered in previous literature including baffle cut ratio, number of holes, holes distribution and baffle spacing. Increasing the baffle size was found to increase the back pressure and shift the peak TL to lower frequencies. Increasing the number of holes in baffles deteriorated the transmission loss compared to centred single hole. However, multiple holes are preferable to reduce the back pressure. Using centred holes was found to be more effective than distributing the holes on the baffle surface. Reducing the baffle spacing was found to enhance the transmission loss at high and medium frequency regions. The transmission loss could be improved by more than $40 \%$ by adjusting the highlighted parameters. The current research proofs that baffle cut ratio could be used as a noise control technique, further investigations are required to understand how this technique is effective for different muffler sizes and types.

\section{Acknowledgements}

The authors would like to thank their colleagues who have contributed to the VExPro project, especially Paul Ross, Marcus Henry, Buta Dhaliwal and Sharwari Pujari (from Unipart) and Prannay Patni, Drs Jesper Christensen, Agnieszka Hudoba, and Katerina Stamou (from Coventry University).

\section{References}

[1] Tao, Z and Seybert, AF."A Review of Current Techniques for Measuring Muffler Transmission Loss" SAE 2003-01-1653, 2003.

[2] Zhou, Z and Copiello D. "Simulation of Exhaust Line Noise Using FEM and TMM", Sound \& Vibration, Vol. 47 No. 9, pp.10-13, 2013.

[3] Parlar Z, Ari Ş, Yilmaz R, Özdemir E, and Kahraman A.“Acoustic and Flow Field Analysis of a Perforated Muffler Design”, International Journal of Mechanical, Aerospace, Industrial, Mechatronic and Manufacturing Engineering; Vol. 7, No.3, pp. 447-451, 2013. 
[4] Coustyx software. "Muffler transmission loss - double expansion chamber", 2016.

[5] Gupta AK." Design validation of the existing muffler's transmission loss results with acoustic simulation tool', International journal of research science \& management, Vol. 3, No.4:pp. 35-40, 2016 a.

[6] Gupta AK. "Comparison of Noise Attenuation Level by Convergent and Divergent Cylindrical Duct with Space Constraints", International Journal of Scientific Research in Science, Engineering and Technology, Vol. 2, No.(2):pp. 778-781, 2016b.

[7] Gupta AK."Simulation of sound transmission loss for rectangular cross section muffler with different aspect ratio in same space", International Journal of Engineering Research, Vol.4, No.2, 2016c.

[8] Mundhe, V and Deore E." Design and optimization of perforated muffler in an automobile exhaust system", International journal of applied research, Vol. 1,No.(8),pp. 390-395, 2015.

[9] Done, V Venkatesham, B, Tamma, B Soni, K, Dey, S Angadi, SVishal GP." Muffler Design for a Refrigerator Compressor". Paper Presented at International Compressor Engineering Conference pp. 1146:1-7, 2014.

[10] Gupta AK. "Observation for transmission loss by applying multiple baffle plates on single expansion chamber: a simulation approach", International Journal of Engineering Research and Modern Education, pp. 2455 - 4200, 2016d.

[11] Roy, T., "Muffler characterization with implementation of the finite element method and experimental techniques". Michigan Technological University, Msc Thesis. 2011.

[12] Horoub, M. "Acoustic Noise control using multiple expansion chambers", King Fahd University of petroleum and minerals.2011.

[13] Middelberg, JM Barber, TJ Leong, SS, Byrne, KP Leonardi, E.," Computational fluid dynamics analysis of the acoustic performance of various simple expansion chamber mufflers". Proceeding of Acoustics.2004.

[14] Ghude, N Malve, A Kotian, K Thawani, M Rukhande, S., "Investigation of Muffler for Noise Reduction", International Journal on Recent and Innovation Trends in Computing and Communication, Vol. 4, No. 4, pp. 35 - 38, 2016.

[15] Gupta, AK Tiwari, A., "Measurement of Sound Transmission Loss on Straight and Zigzag Perforated Concentric Tube Muffler with Constant Porosity", International Journal on Emerging Technologies, Vol. 6, No.2, pp. 35-40, 2015

[16] Jebasinski R.," Calculation of the Tail-pipe Noise of exhaust systems with Wave", Ricardo-wave software, 1996.

[17] Jebasinski R., "Absorption mufflers in exhaust systems”, Ricardo-wave software, 2002.

[18] Cheung R. "Exhaust System Structural Vibration \& Muffler Shell Noise Prediction due to Gas Pulsations in a 2.01 4Cyl DI Diesel Engine", Jaguar Land Rover RS EUC, Prague. 2015.

[19] STAR-CCM+ software.

[20] Cable, M., "An Evaluation of Turbulence Models for the Numerical Study of Forced and Natural Convective Flow in Atria", Master of Science, Queen's University, Canada. 2009.

[21] Montenegro, G, Onorati, A and Torre, AD. "The prediction of silencer acoustical performances by 1D, 1D-3D and quasi-3D non-linear approaches", Computers \& Fluids, Vol. 71, pp. 208-223, 2013.

[22] Siano D. "Three-dimensional/one-dimensional numerical correlation study of a three-pass perforated tube", Simulation Modelling Practice and Theory, Vol. 19, pp. 1143-1153, 2011. 


\title{
Authors' Profiles
}

\begin{abstract}
Ahmed Elsayed has a $\mathrm{PhD}$ degree in thermal engineering from mechanical engineering at the University of Birmingham 2011 experiencing in modelling and testing of boiling and condensation heat transfer. During his career he joined several research projects including adsorption cooling systems for Weatherite Air Conditioning Limited 2012-2014 with Knowledge transfer partner (KTP) project, Stirling engines research program at university of Birmingham 2014-2015, and Computational fluid dynamics analysis for various exhaust systems using OpenFoam at Coventry University 2015-2016. He completed several consultation projects including development of thermosyphon performance software tool for Sterling Thermal Technology, enhanced coated condensers for Alkemy. Dr Elsayed has more than 30 published articles in peer reviewed
\end{abstract} international journals, conferences and 3 book chapters.

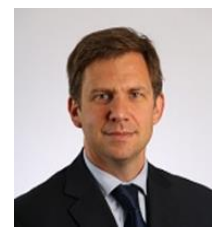

Christophe Bastien worked for Matra Datavision, MSX and Corus as a CAE technical specialist for 13 years. He has contributed to the development of the Jaguar X-Type for interior head impact protection (FMVSS201), as well as for the design and analysis of the Jaguar XK for pedestrian legislation. When he joined Corus, he continued to focus on pedestrian safety and developed new skills in highway engineering design and analysis. During his career, he filed 19 patents in the area of safety engineering. In 2007, he joined Coventry University and is now a principal lecturer in engineering simulations. In 2013 he was awarded a PhD in biomechanics and safety. His current work is focussed in predicting the human pedestrian injury trauma as well as studying the multi-disciplinary and multi-physics optimisation of transport architecture

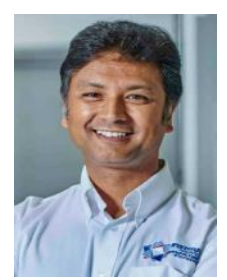

Professor Jones was Rolls-Royce's global engineering specialist providing welding and brazing engineering solutions. His work in developing Rolls-Royce's Shaped Metal Deposition process for producing 3DP-AM jet engine parts led him to receiving the Company's Operational award for innovation, leading to several patents, in addition to the Leslie Lidstone Medal; the Welding Institute's international award for engineers who have made the most significant contribution to welding in the world. Professor Jones has also provided novel electron beam welding solutions applied to aircraft fuel sensory systems and was the main welding advisor for Rolls-Royce Marine systems in producing the shiplift TM manipulating equipment that positioned the Venice MOSE flood barrier. He is also a visiting professor of the University of Sheffield/Nuclear Advanced Manufacturing Centre, a UK contributor to the American Society of Mechanical Engineers Section IX, the UK's representative for Resistance and Solid-State welding as well as brazing and soldering sciences, a working party member of the RCC-M nuclear welding and fabrication committee and Chairman of the Examination Board of The Welding Institute.

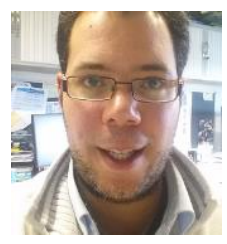

Humberto Medina is a senior lecturer at Coventry University. He obtained his undergraduate and doctoral degrees in Aerospace Engineering from the Queen's University of Belfast. His research interests include experimental and numerical fluid mechanics, applied aerodynamics and their integration into engineering design. 
Hassan Kassem pursued his $\mathrm{PhD}$ degree at City University London working on numerical prediction of transonic fluter of composite aircraft wings. He has a master by research from University of Technology, Malaysia where his research was focused on turbulent combustion modeling. During his research he worked on different modeling problems including fluid-structure interaction, multiphase flow, reacting flow and flow in porous media. Most of his CFD work developed within OpenFOAM framework programming.

How to cite this paper: Ahmed Elsayed, Christophe Bastien, Humberto Medina, Steve Jones, Hassan Kassem,"Enhancing Noise Attenuation in Exhaust Mufflers on Response to Baffle Configuration", International Journal of Engineering and Manufacturing(IJEM), Vol.7, No.4, pp.12-25, 2017.DOI: 10.5815/ijem.2017.04.02 